\title{
Resenha
}

\section{A QUINTA DISCIPLINA}

SENGE, Peter M. A quinta disciplina: arte e prática da organização que aprende.

Ed. Best Seller: São Paulo. 4 ed, 1990.

Athena de Albuquerque Farias (1)

Diana Figueiredo Barbosa (2)

O livro de Peter Senge, evoca a idéia de que, pessoas diferentes, quando em situação de grupo, possuem uma tendência a produzirem resultados semelhantes por conta da auto-influência que sofrem dos componentes do grupo como um todo. Essas interações não se limitariam às pessoas, mas aos valores compartilhados, às crenças, maneiras de agir, tipo e uso da tecnologia empregada na organização, também seriam elementos influenciadores importantes. Segundo o autor, somos prisioneiros de uma estrutura invisível da qual não estamos conscientes, necessariamente.

Quando nos damos conta do quanto estamos envolvidos nessas estruturas organizacionais, iniciamos um processo interno de amadurecimento e libertação, de forma a poder lidar com elas mais apropriadamente.

A proposta das cinco disciplinas é ajudar a organização a aprender como grupo. A se libertar das amarras que impedem as organizações de funcionarem, apesar das suas limitações e, dar-se conta das suas deficiências, de maneira a poder ajudar-se enquanto grupo.

O livro em pauta, tenta responder a uma importante questão sobre administração. Como será a administração dos negócios para o novo século?. Esta é uma questão bastante controversa entre os autores, considerando-se a atual fase de mudanças, tanto sociais quanto tecnológicas, com um grande impacto nas organizações e nas pessoas.

Neste caso, segundo Peter Senge, uma das características fundamentais para sobreviver em meio a esse processo de reorganização sócio-econômica, seria a capacidade de aprender, isto é, ser capaz de reinventar-se para tornar-se mais eficaz. O autor sugere que as novas tecnologias de aprendizagem organizacional dizem respeito a cinco novas habilidades, que o mesmo chama de disciplinas, a saber: 1 - O pensamento sistêmico; 2 O Domínio Pessoal; 3 - Modelos Mentais; 4 - Visão Compartilhada e, 5 - Aprendizagem em grupo.

O primeiro deles, o pensamento sistêmico está ligado ao fato de concebermos o mundo com adventos interrelacionados. A idéia do autor parece ser a de reconhecer as empresas enquanto sistemas, onde todas as pessoas, objetos de trabalho, rotinas e ações estariam conectados. Assim, todas as coisas e pessoas estariam ligadas de maneira não-linear, influenciamdo-se mutuamente como as linhas de uma teia. Esta disciplina diz respeito a um dos pilares da Gestalt, que vê o todo como algo qualitativamente maior que a soma das partes.

A segunda disciplina diz respeito ao domínio pessoal, que segundo o autor, precisamos nos sentir como parte de um processo, onde a tensão gerada pela expectativa do devir e a visualização do ideal desejado, 
funcionam como uma força propulsora capaz de nos motivar a um verdadeiro crescimento emocional e profissional. É o que o autor chama de tensão criativa, que nos permite conscientizar sobre nossos desejos e a realidade do contexto. O domínio pessoal nos permite espantar o pensamento de incapacidade e se aproximar do compromisso com o todo e, portanto, conosco mesmos. Assim, focar nossa energia em metas, nos ajuda a avançar num aprofundamento saudável das nossas qualidades, a medida em que aprendemos com os nossos erros durante esse processo.

A terceira disciplina nos reporta aos modelos mentais inconscientes. A disciplina de modelos mentais, nos auxiliaria a uma melhor avaliação sobre nossa percepção de tudo o que acontece no mundo, de maneira a que nos tornando mais conscientes dos nossos valores e crenças, vamos nos tornando capazes de atualizá-los, à medida que vão ficando obsoletos diante das novas realidades.

As nossas percepções do mundo influenciam nossos julgamentos e as nossas tomadas de atitudes. Quando esses modelos mentais se tornam mais conscientes, é possível uma avaliação para que os mesmos se tornem mais adequados a cada momento. Isto é, conhecendo melhor as nossas dificuldades, podemos influenciar no sentido de minimizá-las, melhorando cada vez mais. Segundo o autor, um líder deveria aperfeiçoar continuamente seus modelos mentais e não impor o seu aos outros.

A quarta disciplina trata da visão compartilhada como fator de união e identificação grupal. Um grupo com visão compartilhada age no grupo, auxiliando seus membros a se responsabilizarem mais pelas tarefas grupais, uma vez que esta reflete uma parte da visão de cada um. A visão compartilhada é geradora de comprometimento, participação e obediência, mas também pode ser fonte de apatia, e relutância. A idéia do autor é difundir a importância de se transformar a visão individual numa visão compartilhada do grupo, enquanto uma organização.

A quinta disciplina se refere a Aprendizagem em grupo e está calcada numa autêntica, solidária e empática interação entre as pessoas. É o oposto da competição, tão estimulada em nossos dias. A aprendizagem em grupo pressupõe dialogicidade e aceitação das diferenças. Trata-se de um processo que visa maximizar os resultados de um grupo, que requer prática e paciência para análise dos diferentes pontos de vista. O grupo é a unidade fundamental de aprendizagem numa organização e não cada pessoa individualmente.

Na segunda parte do livro, o autor refere-se às Leis da Quinta Disciplina. Dentre elas, a afirmação de que os problemas que temos hoje, são provenientes das soluções geradas ontem. Neste caso, refere que algumas soluções não eficazes, reduzem o problema de uma área da organização, causando muitas vezes problema em outra dimensão. E esses nem sempre são detectados a tempo de uma resolução mais eficiente, portanto é preciso ter atenção para com a implementação das soluções. Uma segunda lei, informa que há uma tendência a resistência na manutenção de uma dificuldade, seja ela qual for, quando tentamos debelá-la. Segundo o autor, seria uma espécie de feedback de compensação. A toda ação, há uma tendência de reação de força igual, porém contrária, que às vezes anulam os benefícios da intervenção realizada.

Uma outra Lei da Quinta Disciplina nos orienta que o comportamento melhora antes de piorar. Assim, uma solução que pode parecer eficaz inicialmente, a médio ou longo prazo pode fazer reaparecer o problema de forma mais intensa, sendo de mais difícil resolução. Na sequência, Peter Senge informa que a saída fácil, pode nos conduzir de volta ao ponto inicial. Isto é, as soluções mais conhecidas e mais fáceis, nem sempre são as mais eficazes. A insistência em utilizar soluções mais fáceis, e mais familiares são um indício de falta de criatividade, 
de falta de envolvimento dos componentes do grupo e, portanto, um indicativo de que o pensamento sistêmico não está sendo adotado.

Uma outra Lei da Quinta Disciplina proposta pelo autor é que a cura pode ser pior que a doença. Neste caso, nos alerta para a utilização de soluções não sistêmicas, isto é, soluções não compartilhadas de maneira a envolver o grupo, de tal forma, a responsabilizar todos a motivar-se para que a solução resolva o problema identificado.

Em seguida fala sobre a idéia de que, mais rápido pode significar mais devagar. Neste caso, o autor propõe o pensamento sistêmico como mais promissor, do que uma solução usual para resolver problemas. Apostando que, nem sempre as saídas mais rápidas levam a resultados eficazes. Muitas vezes temos que lidar algum tempo com a dificuldade, de forma a aguardar que uma solução compartilhada seja efetivada e validada por todos os envolvidos.

A lei da causa e efeito, afirma que estes processos não estão intimamente relacionados no tempo e no espaço. Neste caso, há uma diferença entre a realidade e a forma como a percebemos, tanto no tempo, quanto num determinado espaço. Portanto a idéia de que causa e efeito estão próximos no tempo e no espaço deve ser abolida.

Uma idéia-lei é a de que pequenas mudanças podem produzir grandes resultados, mas em geral, as áreas de maiores resultados nem sempre ficam tão evidentes. $\mathrm{O}$ autor nos orienta que, pequenas atitudes bem discutidas e aplicadas adequadamente, tendem a produzirem melhorias significativas. A idéia é pensar uma solução que maximize os resultados com um mínimo de esforço.

Uma outra Lei da Quinta Disciplina proposta por Senge é que você pode assobiar e chupar cana, mas não ao mesmo tempo. Neste caso, o autor nos alerta para o fato de que problemas mais complexos requerem soluções mais compartilhadas e não, necessariamente complexas. Na sequência nos informa que dividir um elefante ao meio não produz dois elefantes pequenos. E por isso, para se compreender determinadas dificuldades organizacionais, é preciso olhar o sistema por inteiro. Olhar por partes, pode resolver o problema de uma dimensão e gerar mais problemas para as outras dimensões.

Por fim, o autor propõe que não existem culpados e, por isso, não há porque gastar energia com a procura das circunstancias externas causadoras. O pensamento sistêmico nos informa que somos todos um, e por isso a organização e as causas e curas de suas dificuldades fazem parte de um mesmo e único sistema.

É uma leitura agradável que ajuda a pensar nosso papel enquanto parte de uma estrutura organizacional. As organizações já se apresentavam como sistemas complexos, a tecnologia da informação adicionou novos fatores de complexidade para a organização e para os seguimentos nos quais ela está inseria. A idéia de formular leis sistêmicas e disciplinas para que as organizações se tornem mais eficientes, possui uma lógica interessante e atual.

É uma obra didática, que serve tanto para iniciantes na administração, para educadores e para aqueles que realmente se importam com o desenvolvimento das pessoas em benefício da organização. 


\section{Sobre as autoras:}

(1) Athena de Albuquerque Farias é Acadêmica de Direito da Faculdade dos Guararapes. Jaboatão dos Guararapes-PE. E-mail: athena.farias@gmail.com

(2) Diana Figueiredo Barbosa é Graduada em Administração de Empresas pela Universidade Estadual do Ceará -UECE -, Pós-graduada em Gestão Empresarial pela Universidade Regional do Cariri -URCA - e Mestre em Administração e Controladoria pela Universidade Federal do Ceará-UFC. Docente nos cursos de Administração e Ciências Contábeis da Universidade Estadual Vale do Acaraú, a nível de Pós-graduação na Faculdade Vale do Salgado nos cursos de Gestão Financeira, Auditoria e Controladoria e no curso de Gestão de Recursos Humanos..

E-mail: dianabarbosaconsultoria@hotmail.com

\section{Como citar este artigo (Formato ISO):}

FARIAS, A. A. e BARBOSA, D. F. Resenha. Id on Line Revista de Psicologia, Novembro de 2011, vol.1, n.15, p. 18-21. ISSN 1981-1189. 